\title{
Genetic neighbourhoods in plants with diverse systems of mating and different patterns of growth
}

\author{
Chris Gliddon*† \\ Eric Belhassen $\dagger$ and \\ Pierre-Henri Gouyon $+\$$
}

\author{
* School of Plant Biology, University College of \\ North Wales, Bangor, Gwynedd, U.K. \\ $\uparrow$ Centre d'Etudes Phytosociologiques et Ecologiques, \\ C.N.R.S., Route de Mende, B.P. 5051, 34033 \\ Montpellier cedex, France. \\ $\ddagger$ I.N.A.P.G., 16, rue Claude Bernard, 75231 Paris \\ cedex 05, France.
}

The neighbourhood model of Wright has become used widely to estimate the effects of locally restricted gene flow in plants. This model is extended to enable estimates of $\sigma^{2}$, the parent to offspring dispersal variance, to be made in plants with a wide variety of sexual systems and with different patterns of vegetative growth. A method of partitioning this variance is given as a general model. The implications of restricted gene flow in natural populations are discussed and attention is drawn to some of the problems attendant upon attempts to measure neighbourhood size.

\section{INTRODUCTION}

The application of gel-electrophoresis and its subsequent refinements to natural populations of animals and plants has shown that, in most species, extremely large amounts of genetic variability exist. This observation has presented many difficulties of interpretation to theoretical population geneticists and has been termed the "paradox of variation" (Lewontin, 1974). However, these observations have been made on assemblages of individuals in nature whose properties deviate frequently from the assumptions of the theoretical models which attempt to explain them. An understanding of the genetic structure of such assemblages, in particular some estimate of their effective population size, is clearly a pre-requisite to assessing the probable importance of the random and non-random forces which define their present state. Crawford (1984a) pointed out the problems of estimation attendant upon measuring effective population size, $N_{e}$.

Attempts to estimate the locally effective population size in plants have generally used the model of the genetic neighbourhood (Wright, 1943, 1946). Wright defined a genetic neighbourhood as the area within which the parents of central individuals may be treated as if drawn at random. His basic model has a single parameter, $\sigma$, the standard deviation of the parent-offspring dispersal distri- bution. Crawford (1984a, b) considered the partitioning of this single parameter to take account of some of the components of dispersal in plant populations. He extended the model to consider various deviations from the assumption of random mating within the neighbourhood. However, his formulation allows only for variability in levels of outcrossing in hermaphrodite individuals and assumes that all gene flow is mediated via pollenand seed-dispersal. It is the purpose of this paper to present two extensions to Crawford's model. This first considers vegetative growth or "reproduction" as a mechanism of gene dispersal and the second examines populations which do not consist entirely of hermaphrodites, that is gynodioecious and dioecious species.

THE MODEL

\section{Vegetative growth}

Wright $(1943,1946)$ defined the genetic neighbourhood area, $N_{A}$, as

$$
N_{A}=4 \pi \sigma^{2},
$$

where $\sigma^{2}$ is the variance of the parent offspring dispersal distribution, assuming zero mean dispersal.

When considering plant populations it is convenient to consider this parent-offspring dispersal 
as consisting of two distinct phases: gametic dispersal, and zygotic (post-fertilisation) dispersal. The method by which these two components may be combined is given by Crawford (1984b). In plant species which show significant amounts of vegetative growth prior to flowering, it is necessary to consider this growth as a component of dispersal. This is shown diagrammatically in fig. 1 .

The effect of this growth on the calculation of the components of the parent-offspring dispersal variance is given in table 1 .

Combining these components and weighting the gametic elements by outcrossing rate to give an average dispersal variance for male and female gametes, the following formula is obtained for parent-offspring dispersal:

$$
\sigma^{2}=\frac{t}{2} \sigma_{p}^{2}+\sigma_{v}^{2}+\sigma_{s}^{2}
$$

where $t$ is the proportion of pollen/ovules outcrossed, $\sigma_{p}^{2}$ is the pollen dispersal variance from flower to flower, $\sigma_{v}^{2}$ is the dispersal variance of flowers from the plant base and $\sigma_{s}^{2}$ is the seed dispersal variance from flower to seed germination site, as shown in fig. 1 .

\section{Gynodioecy}

There are two main problems associated with attempts to estimate the genetic neighbourhood area in a gynodioecious species. Firstly, a floral or seed dimorphism often exists which can cause differences in the magnitude of seed dispersal in the two sexes. Secondly, the outcrossing rate in the population, which modifies the contribution of pollen dispersal to the parent-offspring dispersal
Table 1 Components of parent-offspring dispersal with and without vegetative growth

\begin{tabular}{lll}
\hline Component & $\begin{array}{l}\text { Without } \\
\text { vegetative } \\
\text { growth }\end{array}$ & $\begin{array}{l}\text { With } \\
\text { vegetative } \\
\text { growth }\end{array}$ \\
\hline $\begin{array}{l}\text { Gametic: } \\
\quad \begin{array}{l}\text { Male } \\
\text { Female }\end{array}\end{array}$ & $\sigma_{p}^{2}$ & $\sigma_{p}^{2}+\sigma_{v}^{2}$ \\
Average gametic & 0 & $\sigma_{v}^{2}$ \\
Zygotic: & $\frac{1}{2} \sigma_{p}^{2}$ & $\frac{1}{2} \sigma_{p}^{2}+\sigma_{v}^{2}$ \\
Total & $\sigma_{s}^{2}$ & $\sigma_{s}^{2}$ \\
\hline
\end{tabular}

variance, is a function of the frequency of females in the population as well as a biological attribute of the hermaphrodites.

Consider a population where females and hermaphrodites occur in the proportions $f$ and $(1-f)$ respectively. Let the average proportion of ovules in hermaphrodites which are outcrossed be $t_{h}$, the proportion of successful seed (i.e., those producing seedlings) derived from hermaphrodite flowers be $R_{h}$ and that from female flowers be $R_{f}\left(=1-R_{h}\right)$. Assuming that the numbers of seeds per plant are independent of sex and have equal viability then $t$, the average outcrossing rate in the whole population is given by

$$
t=(1-f) t_{h}+f
$$

and

$$
\begin{aligned}
& R_{f}=f, \\
& R_{h}=(1-f) .
\end{aligned}
$$

However, studies on the evolution of gynodioecy require that there is an increase in the number of

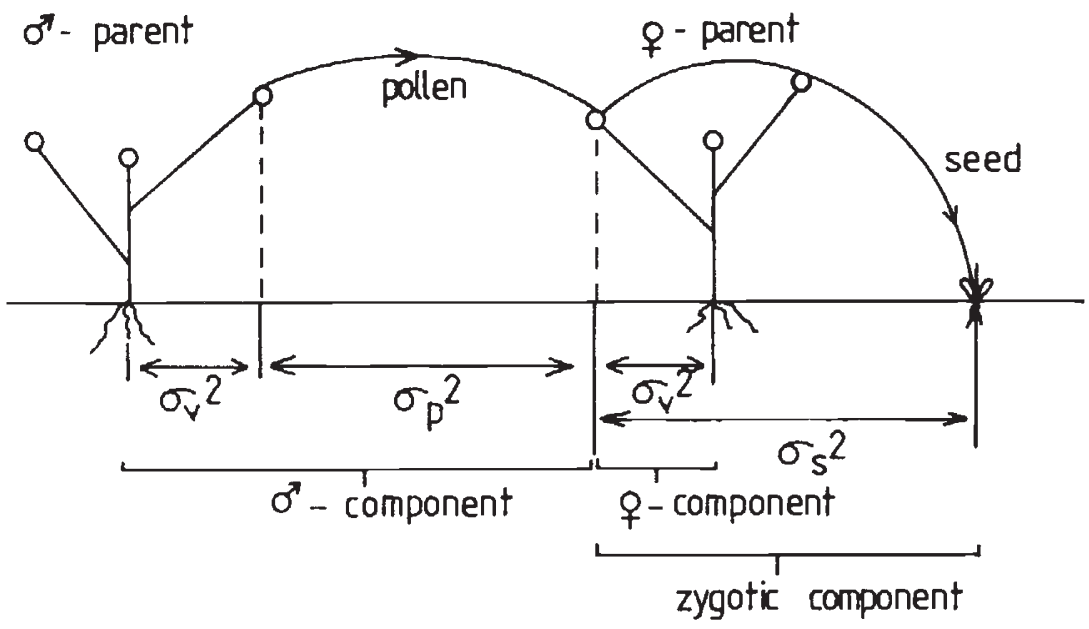

Figure 1 Schematic diagram of gene-flow in plants with vegetative dispersal. 
seeds produced by females, relative to hermaphrodites. This is termed relative female advantage and is quantified by $\times$ (see Lewis, 1941, Gouyon and Couvet, 1985). In addition, there is usually considered to be some inbreeding depression, $d$, on seeds produced by self-fertilisation ( $d$ is the fitness of selfed individuals relative to outcrossed individuals). Under these conditions we have

$$
\begin{gathered}
t=R_{h} \cdot t_{h}+R_{f}, \\
R_{f}=\frac{f . x}{T}
\end{gathered}
$$

and

$$
R_{h}=\frac{(1-f)\left[\left(1-t_{h}\right) \cdot d+t_{h}\right]}{T},
$$

where $T=(1-f)\left[\left(1-t_{h}\right) . d+t_{h}\right]+f . x$, a normalising factor. Using $t, R_{h}$ and $R_{f}$ we can define the average parent-offspring dispersal variance by

$$
\sigma^{2}=\frac{t}{2} \cdot \sigma_{p}^{2}+R_{h} \cdot \sigma_{s h}^{2}+R_{f} \cdot \sigma_{s f}^{2},
$$

where $\sigma_{s h}^{2}$ is the seed dispersal variance from hermaphrodites and $\sigma_{s f}^{2}$ is the seed dispersal variance from females.

\section{The generalised model}

Combining the effects of vegetative growth and gynodioecy from equations (2) and (9) we obtain:

$$
\sigma^{2}=\sigma_{v}^{2}+\frac{t}{2} \cdot \sigma_{p}^{2}+R_{h} \cdot \sigma_{s h}^{2}+R_{f} \sigma_{s f}^{2}
$$

When the proportion of females is zero $(f=0)$, then $R_{h}=1$ and $R_{f}=0$, the formula reduces to equation (2) and becomes that obtained by Crawford $(1984 a, b)$ for hermaphrodites when $\sigma_{v}^{2}=0$. In the case of dioecy $x=\infty$, giving $R_{h}=0$, $R_{f}=1$ and $t=1$. The formula becomes the same as that for hermaphrodites with the substitution of $\sigma_{s f}^{2}$ for $\sigma_{s h}^{2}$. Therefore, equation (10) represents a general formulation for parent-offspring dispersal variance for breeding systems ranging from hermaphroditism, through gynodioecy, to dioecy, including an allowance for vegetative growth.

\section{DISCUSSION}

The use of incorrect formulae for the calulation of genetic neighbourhoods by previous workers has been pointed out by Crawford $(1984 b)$. The failure to take account of growth or vegetative "reproduction" can also lead to serious errors where such dispersal is large, relative to pollenand seed-dispersal. Measurements of pollen and seed dispersal have usually been made on a plant to plant basis in an attempt to confound the effects of growth. That is, the estimate of pollen (seed) dispersal variance has been based on measurements from the centre of the pollen (seed) donor plant to the centre of the seed plant (seedling). Reference fo fig. 1 shows that this approach would yield a pollen dispersal estimate of $\sigma_{p}^{2}+2 . \sigma_{v}^{2}$ and a seed dispersal estimate of $\sigma_{s}^{2}+\sigma_{v}^{2}$. That is, such measurements would overestimate the parentoffspring dispersal variance by $t . \sigma_{v}^{2}$. Many species of plant possess a climbing/scrambling growth habit, have rhizomes or stolons or "reproduce" vegetatively by other means such as bulbils. In such species, the growth component of dispersal may be extremely important. Estimation of the magnitude of gene-flow in Trifolium repens, a stoloniferous plant, showed that growth was the major component of gene-flow in plants over 5 years old (Gliddon and Saleem, 1985).

Estimation of gene-flow parameters in a gynodioecious species, Thymus vulgaris by Belhassen et al. (1987), showed that the floral dimorphism was accompanied by differences in seed dispersal between the two sexes. Earlier workers (Dommee et al., 1983) also noted that the frequency of females changed with age of the population. An examination of equation (10) shows that, for the proportion of females to influence the neighbourhood area, then either:

or

$$
\text { (a) } t_{h}<1 \text {, }
$$

$$
\text { (b) } \sigma_{s f}^{2} \neq \sigma_{s h}^{2} \text {. }
$$

Both of these conditions are met in T. vulgaris (Belhassen et al., 1987) and therefore the magnitude of gene-flow changes with the proportion of females in (or age of) the populations. However, it is interesting to note that in a gynodioecious species, with self-incompatible hermaphrodites and an absence of sexual dimorphism in seed dispersal, the frequency of females in a population would have no effect on the neighbourhood area. Plantago laceolata may represent such an organism (Van Dijk, 1985; Bos, 1986), although Van Damme and Van Delden (1984) reported differences in seed weight between the two sexes which could affect seed dispersal in this anemophilous species.

In most cases of gynodioecy which have been studied, sex appears to be determined by cytoplasmic factors which cause male-sterility and several nuclear genes which have "restorer" alleles for male-fertility. Because the cytoplasmic factors 
are not transmitted through pollen, their parentoffspring dispersal variance, $\sigma_{c}^{2}$, is given by:

$$
\sigma_{c}^{2}=\sigma_{v}^{2}+R_{h} \cdot \sigma_{s h}^{2}+R_{f} \cdot \sigma_{s f}^{2},
$$

which will always be smaller than that of the nuclear genes. That is, the scale of structuring of cytoplasmic genes due to random forces will be smaller than that of nuclear genes.

Estimates of the extent of gene-flow in natural populations are often accompanied by calculations of Wright's $(1940,1943,1946)$ neighbourhood size $\mathrm{N}_{\mathrm{e}}$ (e.g., Kerster and Levin, 1968, Schaal and Levin, 1978, Beattie and Culver, 1979, Cahalan and Gliddon, 1985). It is beyond the scope of this paper to attempt to produce an extension of existing formulae to cover a range of breeding systems. It is, however, necessary to sound a cautionary note with regard to attempts to relate the genetic structuring of a population to its evolutionary consequences. Felsenstein $(1975,1976)$ has drawn attention to the fact that the model of Malécot $(1948,1956)$, and probably that of Wright (1940, $1943,1946)$, contain mathematical inconsistencies in their underlying assumptions. In particular, the assumption of a regular distribution of organisms is inconsistent with the nature of the offspring distribution. Even in the absence of such problems, the calculation of the genetically effective density would be very complex. For example, in a gynodioecious species, which exhibits both female advantage and inbreeding depression, the proportion of females will influence the proportion of outcrossing, the sex ratio and the variance in progeny number between plants. The effects of these on the size of the genetically effective density will not be all in the same direction.

The models presented here allow the variance of parent to offspring diseprsal to be estimated correctly in a very broad range of plant species. In a large population, the flow of neutral or weakly selected genes will be determined primarily by this variance.

Therefore, estimates of this nature allow inferences to be made about the spatial distribution of such alleles. The nature of spatial structuring of allelic frequencies is of particular importance in the generation of null hypotheses (i.e., no selection) against which to test the experimental observation of the distribution of alleles found in natural populations.

\section{REFERENCES}

BEATtie, A. J. AND Culver, D. C. 1979. Neighbourhood size in Viola. Evolution, 33, 1226-1229.

BELHASSEN, E., DOCKES, A.-C., GLIDDON, C. AND GOUYON, P. H. 1987. Dissémination et voisinage chez une espèce gynodioique: le cas de Thymus vulgaris (L.). Génétique, Sélection et Evolutio (in press).

BOS, M. 1986. Gene flow in Plantago. I. Gene flow and neighbourhood size in $P$. lanceolata, Heredity, 56, 43-54.

CAHALAN, C. M. AND GLIDDON, C. 1985. Genetic neighbourhood size in Primula vulgaris. Heredity, 54, 65-70.

COUVET, D. HENRY, J. P. AND GOUYON, P. H. 1985. Sexual selection in hermaphroditic plants: the case of gynodioecy. Amer. Natur., 126, 294-299.

CRAWFORD. T. J. 1984a. What is a population? In Shorrocks, B. (ed.) Evolutionary Ecology, Blackwell Scientific Publications, Oxford, pp. 135-173.

CRAWFORD, T. I. 1984b. The estimation of neighbourhood parameters for plant populations. Heredity, 52, 273-283.

DOMMEE, B. GUillerm, J. L. AND VALDEYRON, G. 1983. Régime de reproduction et hétérozygotie des populations de Thym, Thymus vulgaris L., dan une succession postculturale. C.R. Acad. Sci. Paris, Serie III, 296, 111-114.

FELSENSTEIN, J. 1975. A pain in the torus: some difficulties with models of isolation by distance. Amer. Natur., 109, 359-368.

FELSENSTEIN, J. 1976. The theoretical population genetics of variable selection and migration. Ann. Rev. Genet., 10, $253-280$

GLIDDON, C. AND SALEEM, M. 1985. Gene flow in Trifolium repens. An expanding genetic neighbourhood. In Jacquard, P. Heim, G. and Antonovics, J. (eds.) Genetic Differentiation and Dispersal in Plants, NATO ASI Series G: Ecological Sciences, Vol. 5, Springer-Verlag, Berlin, pp. 293-309.

GOUYON, P. H. AND COUVET, D. 1985. Selfish cytoplasm and adaptation; variations in the reproductive system of thyme. In Haeck, J. and Woldendorp, J. W. (eds.) Structure and functioning of plant populations 2, North Holland Publishing Co., Amsterdam, pp. 299-319.

KERSTER, H. W. AND LEVIN, D. A. 1968. Neighbourhood size in Lithospermum caroliniense. Genetics, 60, 577-587.

LEWIS, D. 1941. Male sterility in natural populations of hermaphrodite plants. New Phytol., 40, 56-63.

LEWONTIN, R. C. 1974. The Genetic Basis of Evolutionary Change. Columbia University Press, New York.

malecot, G. 1948. Les mathématiques de l'hérédité, Masson, Paris. $60 \mathrm{pp}$.

MALECOT, G. 1955. Remarks on decrease of relationship with distance. Cold Spring Harbor Symp. Quant. Biol., 20, 52-53.

VAN DAM ME, J. M. M. AND VAN DELDEN, W. 1984. Gynodioecy in Plantago laceolata L. IV. Fitness components of sex types in different life cycle stages. Evolution, 38, 1326-1336.

VAN DIJK, H. 1985. The estimation of gene flow parameters from a continuous population structure. In Jacquard, P. Heim, G. and Antonovics, J. (eds.) Genetic Differentiation and Dispersal in Plants, NATO ASI Series G: Ecological Sciences, Vol. 5, Springer-Verlag, Berlin pp. 311-325.

WRIGHT, S. 1943. Isolation by distance. Genetics, 28, 114-138. WRIGHT, S. 1946. Isolation by distance under diverse systems of mating. Genetics, 31, 39-59. 